\title{
A response to the critique of gender issues in computer-supported learning
}

\author{
Cathy Gunn,* Sheila French,** Hamish MacLeod,*** Mae McSporran***** and \\ Gráinne Conole****** \\ *University of Auckland **Manchester Metropolitan University ***University of \\ Edinburgh ***** Unitec ******University of Southampton \\ email: ca.gunn@auckland.ac.nz
}

We find the critique of our paper both interesting and informative. The author raises a number of points as a caution against oversimplification of the issues surrounding gender and computer-supported learning. We fully acknowledge the difficulty of reporting findings from a number of studies and of attempting to define or analyse the complex interaction of already complex concepts such as gender, identity and behaviour within computer-supported learning environments.

In response we believe it is important to acknowledge the context in which the article was written: it summarized the research findings of several authors who together ran a discussion panel at the ALT Conference in 2001. The authors come from England, New Zealand and Scotland, have different professional backgrounds and work in different academic disciplines. We brought a variety of converging backgrounds with respect to theories of gender to this collaboration, including cognitive, developmental and experiential (Siann, Durndell, MacLeod and Glissov, 1988; Siann, MacLeod, Glissov and Durndell, 1990). The common interest we share is in the real business of working with students in technologically mediated learning environments. We have concerns, based on direct observations, which we would like others to engage with us about.

Gender issues, we would argue, have not been at the fore of either the ALT journal or Conference. Our purpose with both the panel and the paper was to raise awareness and to bring issues that our own and others' research identify as important to the attention of a wider audience. The paper was neither an in-depth study of gender, nor an analysis of the social and cultural practices which constitute science and technology. This paper was a discussion of the panel's findings from their own experiences with reference to published research from other contexts. Whilst the authors would have liked to explore the issues 
further, the length of the paper as well as the complexity of the issues prevented us from doing so. Fuller reading of the case studies cited can be found in Richardson and French (2001), McSporran, Dewstow and Young (1999) and McSporran and Young (2001).

In our paper, we have tended to universalize gender, particularly for the women in the studies. We have not discussed class, ethnicity, educational background or institutional culture, although our collective experience does make us aware of the impact of these factors. Whilst we argue we have tried to acknowledge such differences, we may appear to have fallen into the trap of essentialism. The difficulties of exploring difference in students without losing the gendered subject, we agree, is complex and problematic. Richardson and French realized in their study that there seemed to be a presence of 'woman', which, as reported, was a minority on the course. The experiences of these women compelled the authors to explore their experiences further. The authors were not blind to these differences but attempted to recognize them, although this was not covered in the short paper. However, the authors also recognize that to explore differences among women perhaps compels us to explore differences among men. This, we suggest, waters down the case of women and challenges the reasons we raised the issues in the first place. The authors acknowledge that this is a complex argument of feminist concern (Alcoff, 1997).

Further difficulties and complexities arise when reporting findings from a group of international authors. We, the authors, are from diverse cultures and different genders. Bringing together findings based on race, ethnicity, our own gendered experience and that of our students is almost impossible. We all have our own subjectivities and the cultural contexts we work in are not comparable. In our individual studies we did find differences in ethnicity and class, which again varied across countries and cultures. For example, Richardson and French found their female students to be mainly under thirty, and of diverse cultures and class. McSporran et al. found the females in their study were mainly working class, predominantly white but including some Asian and other recent immigrant groups, as well as mature students returning to work. Most of these women had seen the usefulness of computers in the workplace and were pragmatic in their choice of courses. However, our discussion revealed that there is no basis for comparison across the UK and New Zealand cultures. Social class and the perceived role of women within these cultures are different, as is the acceptable role of researchers studying cultural groups that they do not belong to. The ethnic mixes are very different, and so the complexity of definition and analysis increases. Comparing - or even discussing - this in such a short piece of work was difficult, if not impossible.

Moving then to the educational aspects, the authors are aware that there is a body of work from authors such as Clegg, Mayfield and Trayhurn (1999) who discuss the many discourses around the field of computing. We recognize that these are also complex and need further exploration, which some of us are pursuing.

To conclude, the discussion raised by Hughes from our original paper has been both stimulating and informative. The suggestions give the authors a further body of work to research should they so wish. We feel these discussions can only help to raise the profile of gender issues in computer-supported learning and hope they will be the start of a new and stimulating dialogue within the ALT arena. We propose that bringing the various discourses of gender, identity and computer-supported learning to the attention of academics in all 
disciplines will support a move towards the breadth of understanding required to address imbalances wherever these exist. A parallel to this is the evolution of the discipline of Human Computer Interaction ( $\mathrm{HCI}$ ) which brought multi-disciplinary perspectives to software design in order for its products to be suitable for, and accessible to non-specialists.

\section{References}

Alcoff, L. (1997), 'Cultural feminism versus post-structuralism: the identity crisis in feminist theory', in L. Nicholson (ed.), The Second Wave: A Reader in Feminist Theory, London: Routledge, 330-55.

Clegg, S., Mayfield, W. and Trayhurn, D. (1999), 'Disciplinary discourses: a case study of gender in information technology and design courses', Gender and Education, 11 (1), 43-55.

McSporran, M., Dewstow, R. and Young, S. (1999), 'Who wants to learn on-line? Identifying our flexible learners', Proceedings of the World Conference on Educational Multimedia, Hypermedia and Telecommunications Conference, Washington.

McSporran, M. and Young, S. (2001), 'Does gender matter in online learning?', ALT-J, 9 (2), 3-11.

Richardson, H. J. and French, S. (2001), 'Education on-line: what's in it for women?', in E. Balka and R. Smith (eds), Women, Work and Computerisation: Charting a Course to the Future, Boston: Kluwer.

Siann, G., Durndell, A., Macleod, H. and Glissov, P. (1988), 'Stereotyping in relation to the gender gap in participation in computing', Educational Research, 30, 98-103.

Siann, G., Macleod, H., Glissov, P. and Durndell, A. (1990), 'The effect of computer use on gender differences in attitudes to computers', Computers in Education, 14 (2), 183-91. 